\title{
Quality of life of frail elderly users of the primary care
}

\section{Qualidade de vida de idoso fragilizado da atenção primária}

\author{
Maria Helena Lenardt ${ }^{1}$ \\ Nathalia Hammerschmidt Kolb Carneiro ${ }^{1}$ \\ Jéssica Albino ${ }^{1}$ \\ Mariluci Hautsch Willig ${ }^{1}$
}

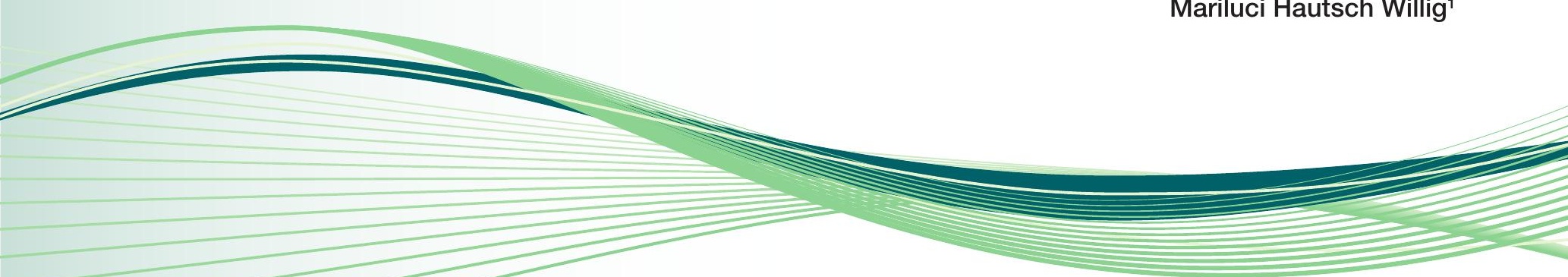

Frail elderly: Quality of life; Geriatric nursing; Primary nursing; Primary health care; Questionnaires

Descritores

Idoso fragilizado; Qualidade de vida; Enfermagem geriátrica; Enfermagem primária; Atenção primária à saúde; Questionários

Submitted June 24, 2014

Accepted June 30, 2014

\begin{abstract}
Objective: Identifying the quality of life of frail elderly patients, users of primary care services.

Methods: A cross-sectional, quantitative study. The sample size was calculated based on the estimate of population proportion and consisted of 203 elderly. Data were collected by using a questionnaire of physical activity for the elderly, fatigue/exhaustion, quality of life, and by carrying out a test of gait speed, handgrip strength and anthropometric measurement.

Results: Among the 203 seniors, 39 were fragile. The mean scores for quality of life presented by the frail elderly were the following: 60.4 for pain, functional capacity 61.1 , limitations due to physical aspects 71.1 , general state of health 71.4, vitality 75, mental health 76.4, emotional aspects 81.1 and social aspects 85.6. Conclusion: The dimensions of quality of life of the frail elderly that had lower mean scores were pain, functional capacity, limitations due to physical aspects and general state of health.
\end{abstract}

\section{Resumo}

Objetivo: Identificar a qualidade de vida de idosos frágeis usuários da atenção primária.

Métodos: Estudo quantitativo transversal. A amostra foi calculada com base na estimativa da proporção populacional e constituída por 203 idosos. Os dados foram coletados mediante questionário de nível de atividade física para idosos, fadiga/exaustão, qualidade de vida e realização de teste de velocidade da marcha, força de preensão manual e medição antropométrica.

Resultados: Dos 203 idosos, 39 deles eram frágeis. As médias de qualidade de vida apresentadas pelos idosos frágeis foram: 60,4 para dor, 61,1 capacidade funcional, 71,1 limitações por aspectos físicos, 71,4 estado geral de saúde, 75 vitalidade, 76,4 saúde mental, 81,1 aspectos emocionais e 85,6 aspectos sociais. Conclusão: As dimensões da qualidade de vida dos idosos frágeis que apresentaram menores médias foram dor, capacidade funcional, limitações por aspectos físicos e estado geral de saúde.

\section{Corresponding author}

Nathalia Hammerschmidt Kolb Carneiro Quinze de Novembro street, 1299,

Curitiba, PR, Brazil.

Zip Code: 80060-000

nathalia.kolb@gmail.com
DOI

http://dx.doi.org/10.1590/1982-

0194201400067
'Universidade Federal do Paraná, Curitiba, PR, Brazil.

Conflicts of interest: no conflicts of interest to declare. 


\section{Introduction}

The increased longevity of the population causes people to think more deeply about the aging process and its effects on quality of life. A study with subjects aged 65 years or more aimed at assessing the perception of the elderly about their quality of life, pointed out that the majority considered 'being healthy' and 'not having disabilities' as the main definitions of the term. ${ }^{(1)}$ Answers like 'having energy', 'being happy' and 'proper functioning of the senses' were also found. (2) Although quality of life is defined in different ways, there is a consensus that it is a multidimensional concept that includes psychological, social, environmental and spiritual dimensions. ${ }^{(2)}$

One of the most widely used instruments to assess health-related quality of life is the SF-36 (Medical Outcomes Study 36-Item Short-Form Health Survey), developed from the Medical Outcomes Study (MOS), a questionnaire published in English in the year 1990 that is specific to the elderly population. In Brazil, the SF-36 was translated and validated in a study that examined the quality of life of individuals with rheumatoid arthritis. ${ }^{(3)}$ According to the author, it was adapted for use in the Brazilian population considering the local socioeconomic and cultural conditions.

The SF-36 is a questionnaire of easy application. Because of its reproducibility and validity, the questionnaire is an additional parameter for assessing the quality of life of individuals with different pathologies, in research and assistance. ${ }^{(3)}$ One of the health conditions evaluated in this study and associated with the SF-36 was the syndrome of physical frailty in older adults.

The syndrome of physical frailty can be defined as 'a medical syndrome with multiple causes and contributions, which is characterized by a diminution of strength, endurance and reduced physiological function that increases the vulnerability of individuals and develops greater dependence and/ or death'.(4) According to the authors, from this physical focus, frailty can be evaluated through five physical components: unintentional weight loss, reduced grip strength, decreased physical activity, self-reported fatigue and decreased gait speed. Older people who present three or more of these features are considered frail; those with one or two are pre-frail and those who do not have any of these components are non-frail seniors. ${ }^{(5)}$

Although the relations between aging, frailty and quality of life have been little explored, a recent number of studies connects the frailty syndrome with a worsened quality of life. ${ }^{(6,7)}$ Studies evaluating the frailty syndrome through the five physical components and the quality of life through the SF36 , observed that frail elderly had lower scores in almost all dimensions of quality of life when compared to other participants. ${ }^{(8-10)}$ However, it is not yet a consensus that the frailty syndrome negatively influences the quality of life of individuals.

The frail elderly are vulnerable to unhealthy outcomes and therefore, they can express different combinations of quality of life. Little is known about the quality of life of Brazilian frail elderly, about the specific affected aspects, the deficits, the personal compensations and available resources. Hence, studies investigating the quality of life associated with frailty are needed. Through the results of these studies it will be possible to support a more independent life for elderly and to base preventive actions taken by health professionals, focusing on aspects related to frailty and quality of life. ${ }^{(11)}$

Given the above and the national deficit in studies that assess the frailty syndrome by the physical phenotype, the objective of this study was identifying the quality of life of frail elderly patients, users of primary care services.

\section{Methods}

This is a quantitative, cross-sectional study carried out in a Basic Health Unit, which is part of the primary health care service, located in Curitiba, state of Paraná, southern region of Brazil. The target population consisted of elderly aged 60 years and over, in the period between January and April 2013.

The following inclusion criteria were adopted for the selection of the elderly: a) age equal to or 
over 60 years; b) getting a score higher than the cutoff point (according to the level of education) in the cognitive test called Mini-Mental State Examination. ${ }^{(12,13)}$ The exclusion criteria were: a) having previous diagnoses of diseases or serious physical and mental deficits that prevented the participation in the stages of interview and assessment of the frailty phenotype; b) having previously participated in the research.

This was a convenience sample and individuals were invited to participate in the study according to their order of arrival in the health service. The Mini-Mental State Examination was taken in a private environment for tracking the changes in cognitive function (cognitive screening) of the elderly. ${ }^{(12,13)}$ In this study was used the validated version with the following cutoff points: 13 for illiterates, 18 for medium and low education and 26 for high levels of education. ${ }^{(13)}$ The Mini-Mental State Examination comprises 11 items grouped into seven categories: temporal orientation, spatial orientation, registration of three words, attention and calculation, memory of three words, language and visual construction capacity. The scores range between zero and 30.

Data collection included the assessment of the frailty syndrome and evaluation of the health related quality of life of the elderly. In order to make the specificity of elderly Brazilians effective, two changes were made in the evaluation of measures of the frailty phenotype. According to American researchers and their collaborators, the Minnesota Leisure Activity Questionnaire is applied to identify the level of physical activity. For assessing the level of energy, specifically for the fatigue/exhaustion component, these authors use two questions of the Center for Epidemiologic Studies Depression Scale - CES-D. ${ }^{(5)}$ In the present study was applied the Level of of Physical Activity for the Elderly CuritibAtiva questionnaire for the physical activity component. ${ }^{(14)}$ The energy level was known through a question of the Geriatric Depression Scale - GDS, and by a graduated visual scale, using a numbered rule. ${ }^{(15)}$

The unintentional weight loss component was measured by the self-report of weight loss equal to or greater than $4.5 \mathrm{~kg}$ or $5 \%$ of body weight within the last year. The gait speed test was used to measure the slowness in seconds (distance of $4 \mathrm{~m}$ ) with adjustment for gender and height. The handgrip strength was measured with a dynamometer in the dominant hand with adjustment for gender and body mass index - BMI.

The Medical Outcomes Study - MOS, Short Form 36 - SF-36, was used for assessing the health related quality of life. This is an instrument consisting of 36 questions; a question of comparison between the current and previous health, and 35 questions classified into eight domains: physical functioning, role-physical, bodily pain, general health, vitality, social functioning, role-emotional and mental health. The final score ranges from zero to 100 , with higher scores indicators of positive health perception. The instrument was validated for the Portuguese language and is called "Brazil - SF-36". ${ }^{(3)}$

The sample size was determined based on the estimate of population proportion. The confidence level was set at 95\% $(\alpha=0.05), 0.12$ variance and sampling error was fixed at five percentage points. It was added $10 \%$ to the sample size, for the possibilities of losses and refusals, resulting in a sampling plan consisting of 203 elderly.

Data were organized in the $\operatorname{Excel}^{\oplus} 2007$ program and the EpiInfo version 6.04 was used for statistical analysis of data: absolute and percentage frequency distribution, mean and standard deviation.

The development of study followed the national and international standards of ethics in research involving human beings.

\section{Results}

The study included 203 elderly patients, of whom 39 (19.2\%) were classified as frail, $115(56.7 \%)$ as pre-frail and $49(24.1 \%)$ as non-frail.

The highest mean score for quality of life of frail elderly was for the psychosocial dimensions - concerning social aspects, emotional aspects, vitality and mental health. The lowest mean score was for the physical dimensions - concerning pain, func- 
tional capacity, limitations due to physical aspects and general state of health (Table 1).

Table 1. Quality of life of frail elderly

\begin{tabular}{lcc}
\hline \multirow{2}{*}{ Dimensions of quality of life } & \multicolumn{2}{c}{ Frail elderly } \\
& Mean (SD) & Observed variation \\
\hline Functional capacity & $61.1(27.9)$ & $0-100$ \\
Limitation due to physical aspects & $71.1(41.1)$ & $0-100$ \\
Pain & $60.4(30.7)$ & $0-100$ \\
General state of health & $71.4(17)$ & $32-97$ \\
Vitality & $75(24.4)$ & $15-100$ \\
Social aspects & $85.6(25.6)$ & $0-100$ \\
Emotional aspects & $81.1(36.5)$ & $0-100$ \\
Mental health & $76.4(23.4)$ & $20-100$ \\
\hline
\end{tabular}

The quality of life of frail elderly by position is shown in chart 1 . It is observed that the pain dimension of quality of life is the worst evaluated and the social aspect dimension is the best evaluated.

Chart 1. Quality of life of frail elderly by position

\begin{tabular}{|c|c|c|}
\hline \multirow{9}{*}{ 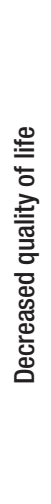 } & $\begin{array}{l}\text { Dimension position } \\
\text { (from lowest to highest score) }\end{array}$ & $\begin{array}{l}\text { Frail elderly } \\
\text { (score) }\end{array}$ \\
\hline & $1^{\text {st }}$ Position & Pain (60.4) \\
\hline & $2^{\text {nd }}$ Position & Funtional capacity (61.1) \\
\hline & $3^{\text {rd }}$ Position & Physical aspects limitations (71.1) \\
\hline & $4^{\text {th }}$ Position & General state of health (71.4) \\
\hline & $5^{\text {th }}$ Position & Vitality (75) \\
\hline & $6^{\text {th }}$ Position & Mental health (76.4) \\
\hline & $7^{\text {th }}$ Position & Emotional aspects (81.1) \\
\hline & $8^{\text {th }}$ Position & Social aspects (85.6) \\
\hline
\end{tabular}

\section{Discussion}

The limits of the study results are related to the cross-sectional design that does not allow establishing relations of cause and effect. On the other hand, the results could guide gerontological nursing care in the practice with frail, pre-frail and non-frail elderly. The studies on the syndrome of frailty and quality of life of seniors subsidize the provision of care for successfully combating the frailty, and consequently resulting in improved quality of life for these individuals.

When compared to national and international studies, the frequency distribution of frailty in this study is significantly high (19.2\%). A study with 606 Americans aged 65 years or more, in which 301 participants were of Mexican ancestry and 305 of European descent, found $12.2 \%$ and $7.3 \%$ of frail elderly, respectively. ${ }^{(16)}$ Another study carried out in Spain with a sample of 814 elderly (aged 65 years or more), found $10.3 \%$ of frail elderly. ${ }^{(17)}$ The pioneering study carried out in Brazil on Frailty in Brazilian Elderly, consisting of a sample of 3,413 individuals aged 65 years or over, revealed $9.1 \%$ of frail elderly. ${ }^{(18)}$

The cultural difference is considered a determining factor. Researchers claim that the unequal distribution of frailty in different places, besides reflecting possible differences in health between countries and regions, can also be attributed to the cultural characteristics that influence the perception of health and interpretation of subjective items of the scales used to assess frailty. ${ }^{(19)}$ Issues relating to lifestyle, nutrition, hydration, presence of comorbidities and medication use may also have influenced the divergence of results.

The dimensions of quality of life of the frail elderly most affected by the frailty syndrome resemble those found in the research conducted with a sample of 1,008 American elderly of Mexican descent aged 74 years or more. ${ }^{(8)}$ The study on the relation between the frailty syndrome and the quality of life of older people using the Medical Outcomes Study - MOS Short Form 36, concluded that the frail elderly of the sample had lower mean scores in the aspects of functional capacity, limitations due to physical aspects and general state of health.

The biological nature of the frailty syndrome itself justifies the significant deficit in the physical dimension of quality of life of frail elderly. In the cycle of frailty, physical problems such as sarcopenia, multiple diseases, excessive use of medication, and neuroendocrine deregulations are directly related with frailty and, consequently, affect the quality of life of these individuals. Moreover, the decline of different physical components that occurs in the syndrome may contribute to this result. Studies have shown that the decrease in physical activity, ${ }^{(20,21)}$ handgrip strength, ${ }^{(9,10)}$ gait speed $^{(9,10)}$ and energy ${ }^{(2,9)}$ are directly related to decreased quality of life. Identifying the 
components of frailty associated with the quality of life of frail elderly is an important first step, as it will lead to the early detection of the involved problems and the establishment of interventions and preventive actions. ${ }^{(11)}$

Unlike other studies, the dimension of pain had the lowest mean score of all investigated dimensions (60.4 points). ${ }^{(8,10)}$ Pain in aging is related to symptoms that are precursors of decline of health and of bodily functions. Physical changes inherent to the frailty of the elderly can be associated with a reduction in health related quality of life, with the lowest mean scores for the pain dimension of the SF-36. ${ }^{(9)}$ The early identification of pain and the use of analgesic drugs may be important factors in the prevention of frailty and increase in quality of life.

A study shows that physical activity practice can improve the condition of frailty in the elderly and therefore, functional capacity. ${ }^{(22)}$ Thus, prescriptions for physical activity according to the possibility of individuals, could act both in the prevention of frailty syndrome as in improving the quality of life of frail elderly. Also, engaging in physical activity can improve mental health and promote social contacts, ${ }^{(20)}$ which is also beneficial for the psychosocial dimensions of the quality of life of seniors.

The psychosocial dimensions have obtained the best scores in the quality of life of frail elderly, a result of the social relations maintained by most of them. The main feature of the psychosocial profile is to be living with relatives or with the spouse and not feeling alone. Many Brazilian elderly still have an important role in the maintenance of themselves and their families. ${ }^{(20)}$ These factors lead the elderly to maintain an active social life, reducing isolation, dependency, thus obtaining better scores on quality of life regarding the psychosocial dimensions. Risk factors involving social relations are strongly associated with moderate or severe dependence. Although the frailty syndrome is a risk factor for dependence, maintaining social relationships can reduce or postpone this scenario.

A national study carried out with 113 participants aged between 60 and 98 years found that seniors with a routine concern with their network of friends and family had better quality of life. ${ }^{(21)}$
According to the author, the ability of the elderly to remain active in the society and for their loved ones transcends the limitations and physical disabilities, while the inability to alter the physical environment becomes inefficiency, lack of motivation and lower levels of quality of life.

\section{Conclusion}

The frail elderly had lower mean scores for the physical dimensions of quality of life such as pain, functional capacity, limitations due to physical aspects and general state of health. The highest mean scores were obtained in psychosocial dimensions, concerning social aspects, emotional aspects, vitality and mental health.

\section{Acknowledgements}

Research carried out with the Support of Scientific and Technological Development of Paraná Fundação Araucária (FA), under protocol number 18239, contract 005/2011.

\section{Collaborations}

Lenardt MHL; Carneiro NHK; Albino J and Willig $\mathrm{MH}$ contributed to the project design, analysis and interpretation of data, drafting the article and critical review of the relevant intellectual content and final approval of the version to be published.

\section{References}

1. Paskulin LM. Elders' perception of quality of life. Acta Paul Enferm. 2010; 23(1):101-7. Portuguese.

2. Molzahn A, Skevington SM, Kalfoss M, Makaroff KS. The importance of facets of quality of life to older adults: an international investigation. Qual Life Res. 2010; 19:293-8.

3. Ciconelli RM, Ferraz MB, Santos WS, Meinão IM, Quaresma MR. [Brazilian-Portuguese version of the SF-36. A reliable and valid quality of life outcome measure]. Rev Bras Reumatol. 1999; 39(3):143-50. Portuguese.

4. Morley JE, Vellas B, Kan AV, Anker SD, Bauer JM, Bernabei R, et al. Frailty Consensus: A call to action. JAMDA . 2013; 14:392-97.

5. Fried LP, Tangen CM, Walston J, Newman AB, Hirsch C, Gottdiener J, et al. Cardiovascular Health Study Collaborative Research Group. Frailty in older adults: Evidence for a phenotype. J Gerontol A Biol Sci Med Sci. $2001 ; 56$ A(3):146-56. 
6. Fillit H, Butler RN. The frailty identity crisis. J Am Geriatr Soc. 2009; $57: 348-52$.

7. Bilotta $C$, Bowling $A$, Casè $A$, Nicolini $P$, Mauri $S$, Castelli $M$, et al. Dimensions and correlates of quality of life according to frailty status: a cross-sectional study on community-dwelling older adults referred to an outpatient geriatric service in Italy. Health Qual Life Outcomes. 2010; 8:56.

8. Masel MC, Graham JE, Reistetter TA, Markides KS, Ottenbacher KJ. Frailty and health related quality of life in older Mexican Americans. Health Qual Life Outcomes. 2009;23(7):70.

9. Lin CC, Li Cl, Chang CK, Liu CS, Lin CH, Meng NH, et al. Reduced health related quality of life in elders with frailty: A cross-sectional study of community-dwelling elders in Taiwan. Plos One. 2011; 6(7):e21841.

10. Chang YW, Chen WL, Lin FG, Fang WH, Yen MY, Hsieh CC et al. Frailty and Its Impact on health-related quality of life: A cross-sectional study on elder community-dwelling preventive health service users. Plos One. 2012; 7(5):e38079.

11. Gobbens RJ, Luijkx KG, Van Assen MA. Explaining quality of life of older people in the Netherlands using a multidimensional assessment of frailty. Qual Life Res. 2013; 22:2051-61.

12. Folstein MF, Folstein SE, McHugh PR. "Mini-mental state": a practical method for grading the cognitive state of patients for the clinician. $J$ Psychiatr Res. 1975; 12(3):189-98.

13. Bertolucci PH, Brucki SM, Campacci SR, Juliano Y. The Mini-Mental State Examination in a general population: impact of educational status. Arq Neuropsiquiatr. 1994;52(1):1-7.

14. Rauchbach R, Wendling NM. Evolution of construction of an instrument to assess the level of physical activity for seniors - CuritibAtiva. FIEP
Bulletin On-line. 2009; 79:543-7. Portuguese.

15. Almeida OP, Almeida SA. Reliability of the Brazilian version of the Geriatric Depression Scale (GDS) short form. Arq Neuropsiquiatr. 1999; 57(2B):421-6. Portuguese.

16. Espinoza SE, Jung I, Hazuda H. Lower Frailty Incidence Among Mexican American than Among European American Older Adults: The San Antonio Longitudinal Study of Aging. J Am Geriatr Soc. 2010; 58(11):2142-8.

17. Alcalá MV, Puime AO, Santos MT, Barral AG, Montalvo Jl, Zunzunegui MV. Prevalence of frailty in an elderly Spanish urban population. Relationship with comorbidity and disability. Aten Primaria. 2010; 42(10):520-7.Spanish.

18. Neri AL, Yassuda MS, Araújo LF, Eulálio MC, Cabral BE, Siqueira ME, et al. Methodology and social, demographic, cognitive, and frailty profiles of community-dwelling elderly from seven Brazilian cities: the FIBRA Study. Cad Saúde Pública. 2013; 29(4):778-92. Portuguese.

19. Santos-Eggimann B, Cuénoud P, Spagnoli J, Junod J. [Prevalence of frailty in middle-aged and older community-dwelling Europeans living in 10 countries]. J Gerontol A Biol Sci Med Sci. 2009; 64(6):675-81.

20. Paskulin L, Vianna L, Molzahn AE. Factors associated with quality of life of Brazilian older adults. Int Nurs Rev. 2009;56(1):109-15.

21. Timm LA, Argimon IIL, Wendt GW. Correlation between domains of quality of life and locus of health control in community resident elderly. Sci Med. 2011;21(1): 9-13. Portuguese.

22. Cameron ID, Fairhall N, Langron C, Lockwood K, Monaghan N, Aggar $\mathrm{C}$, et al. A multifactorial interdisciplinary intervention reduces frailty in older people: randomized trial. BMC Medicine. 2013; 11:65. 